\title{
Economic development and female labor participation in the Middle East and North Africa: a test of the U-shape hypothesis
}

Paolo Verme

Correspondence:

pverme@worldbank.org

The World Bank, 1818 H St,

Washington, DC, 20433, USA

\begin{abstract}
The Middle East and North Africa (MENA) region is known for having low female labor market participation rates compared with its level of economic development. A possible explanation is that countries in this region do not follow a U-shape relation between female participation and GDP during the process of economic development as initially proposed by Goldin (Investment in Women's Human Capital and Economic Development 1995) and observed elsewhere. This paper tests the U-shape hypothesis for the MENA region and finds that the region has outperformed other world regions in terms of the main drivers of the hypothesis, but there is no clear evidence of a U-shape.
\end{abstract}

JEL codes: F66; J13; J16; J21.

Keywords: Labor market; Participation models; Fertility; Economic transformation; Female education

\section{Introduction}

Studies on female labor market participation can be broadly divided into two groups: studies that look at the long-term factors that drive Female Participation Rates (FPR) over periods spanning decades and focus on epochal transformation of societies such as structural changes in the economy, and there are studies that use shorter time periods or simply cross-section information to derive associations between FPRs and other factors that can vary over the short-term such as education or marriage. To the first group belong studies that have been largely pioneered by Ester Boserup and Claudia Goldin. To the second group belong a wide variety of studies on female labor supply and participation. This paper will focus on the first body of literature.

The prevalent hypothesis about the long-term relationship between economic development and FPRs is the U-shape hypothesis (Boserup, 1970, Durand, 1975; Psacharopoulos and Tzannatos, 1989; Goldin, 1995). This broadly states that during the early stages of economic development, FPRs decline due to the initial structural changes of the economy and the transition from an agricultural to an industrialized society, while it increases in later stages when countries mature into modern economies, fertility rates decline and female education rates increase. The literature points to essentially five factors explaining the U-shape hypothesis: 1) the economic transformation of societies from agriculture to industry; 2) the increasing share of the female educated population; 3) long-term demographic changes including falls in fertility rates; 4) cohorts effects; and 5) evolving gender

(c) 2015 Verme; licensee Springer. This is an Open Access article distributed under the terms of the Creative Commons Attribution License (http://creativecommons.org/licenses/by/4.0), which permits unrestricted use, distribution, and reproduction in any medium, provided the original work is properly credited. 
norms and culture. Thanks to the increasing availability of long time-series, these factors and their role in explaining FPRs can now be tested for a wide variety of countries.

The purpose of this paper is to test the U-shape hypothesis in the context of Middle East and North African (MENA) countries following the leads that the literature has provided across countries and within countries over the past thirty years. To our knowledge, there is only one short paper that recently tested the U-shape hypothesis in MENA countries (Tsani et al, 2013). This paper exploits the FPR statistical difference of this group of countries vis-à-vis other world countries to simulate with a Computerized General Equilibrium (CGE) model the outcome of alternative GDP growth and FPR scenarios. It finds potential beneficial effects on growth when removing region specific barriers to female participation. The present paper follows the more standard approach of testing the U-shape hypothesis with parametric and nonparametric methods and assesses each of the main factors behind the U-shape hypothesis one at a time.

FPRs remain one of the puzzles in the development process of MENA countries. The 20 years that predated the Arab spring were characterized by tremendous structural transformation of the economies with stabilization, liberalization and privatization reforms starting in the 1990s, which delivered sustained growth throughout the first decade of the 2000s. This same period also saw unprecedented gains in female education accompanied by sharp falls in fertility rates. Yet, this period has also been characterized by moderate growth in terms of employment and FPRs, with women and youth being the two groups benefitting the least from the growth process. It is therefore compelling to take a longterm view of FPRs, and the factors that help explain FPRs, to better understand the roots of the anomaly represented by the MENA region.

The paper is organized as follows. The next section reviews theory and evidence of the U-shape hypothesis. The following two sections describe models and data respectively. Section 2 presents results, and section 3 concludes.

\subsection{Theory and evidence}

The prevalent hypothesis about the long-term relationship between economic development and FPR is the U-shaped hypothesis (Boserup, 1970, Durand, 1975; Psacharopoulos and Tzannatos, 1989; Goldin, 1995). This broadly states that during the early stages of economic development, FPRs decline due to the initial structural changes of the economy and the transition from an agricultural to an industrialized society. FPRs then increase in later stages when countries mature into modern economies, fertility rates decline and female education rates increase. This is how Goldin (1995) states the hypothesis:

"Across the process of economic development the adult women's labor force participation rate is u-shaped. When incomes are extremely low and when certain types of agriculture dominate (...), women are in the labor force to a great extent. They are sometimes paid laborers but more often unpaid workers on family farms and in household businesses, often doing home workshop production. As incomes rise in most societies, often because of an expansion of the market or the introduction of new technology, women's labor force participation rates fall. Women's work is often implicitly bought by the family, and women then retreat into the home, although their hours of work may not materially change. (...) But as female education improves and as the value of women's time in the market increases still further, relative to the price 
of goods, they move back into the paid labor force, as reflected in the move along the rising portion of the U-shaped curve." (p. 62)

The U-shaped hypothesis has found consistent support in data and analyses since it was first proposed, and this applies to cross-country studies as well as to time-series and panel studies. Among cross-country studies, Goldin (1995) found this relationship to hold for 1980 and 1985 across a group of more than one hundred countries. Mammen and Paxson (2000) replicated Goldin's results for 1980 and 1985 and extended the test to 1970 and 1975, reaching the same conclusion. This paper also pinpointed that the lowest participation rate is found for countries with annual per capita income around $\$ 2,500$, essentially middle-income countries according to the World Bank classification of the time. Similar results have also been found by Tam (2011) for a panel of 134 countries for the period 1950-1980 and by Tsani et al. (2013) for South Mediterranean countries.

Results from time-series studies in developed economies also support the U-shaped hypothesis. Goldin found initial evidence of the U-shape relation in a study on the US (Goldin, 1995). These results were confirmed in more recent studies (Goldin, 2004, 2006, Olivetti, 2013) that were also able to pinpoint five distinct phases characterizing the evolution of FPRs in the US. The first phase ("The independent female worker", up to the 1920s) saw the entrance of young and low educated women into the labor force, mostly in poorly paid or non-paid occupations followed by a subsequent exit from the labor force explained by marriage and the shift to home work. In a second phase (1930s-1950) married women start to join the labor force due to the increased demand in clerical jobs and the increased level in female education. In the third phase (1950s-1970s), FPRs go through a real revolution, with rapid increases explained by better education of women, rising wages and the introduction of more flexible working arrangements such as part-time work.

Time-series evidence for countries other than the US are still scarce, but similar results to the US have been found by Tilly and Scott (1987) for England and France. The U-shaped hypothesis has also been studied in developing economies with time-series data, although these series are typically much shorter than in developed economies. Mammen and Paxson (2000) provide some evidence for the U-shaped hypothesis in Thailand and India. Using cross-country longitudinal data with country fixed effects, these authors found the U-shaped relation to hold for the period 1970-1985 (although the turning point of the $U$ curve lowers to $\$ 1,600$ ).

Only one recent paper has questioned the U-shaped hypothesis (Gaddis and Klasen, 2013). This paper used cross-country data for the period 1980-2005 and found that results related to the U-shape hypothesis are very sensitive to the data source used and that they tend to disappear with the use of panel data. The paper also finds a great heterogeneity of results across countries, little support for the structural change hypothesis from agriculture to industry as an important factor in driving declining FPRs and a more relevant role for sector specific growth rates as opposed to GDP growth. It recognizes, however, the role of fertility and education in explaining rising FPRs on the positive side of the $U$ curve.

While the declining portion of the $U$ curve is mainly explained in terms of the structural transformation of the economy from agriculture to industry, the explanation of the rising part of the curve relies on a more complex combination of factors. Fertility has been 
among the first factors to be identified (Goldin 1995), a factor that found consistent evidence in subsequent studies (Angrist and Evans, 1998; Bloom et Al., 2009). Similarly, female education was detected early on as a major factor of rising FPRs (Goldin, 1995), and matching evidence was found over the years across countries. These two factors are also related to each other (female education delays marriage and pregnancies), so identifying the specific contribution of each factor on FPR is not straightforward. However, the evidence is rather solid in determining a correlation between fertility and education and FPRs cross-country and longitudinally.

A more controversial set of factors relates to culture, gender norms and identity. Akerlof and Kranton (2000) made a convincing case of identity being a major driver in female labor participation: "Similarly women's assumed lower desire for labor force participation (...) can be understood as the result of their identity as homemakers" (p. 732). Goldin (2006) indicated two major factors that could explain the gains in female labor participation in the US during the 1970s and 1980s described as "expanded horizons" (an increase in women's expectations that leads to a change in educational choices) and "altered identities" (an increase in women's decisional power in relation to labor market choices within the family). These changes were largely the product of a cultural revolution that revolutionized female marriage age, college graduation rates and professional school enrollments, all factors occurring in the 1970s. US data clearly show a turning point around 1970 followed by the fast increase in FPRs between 1970 and 2000. The factors that led to the cultural revolution of the 1960s may be debatable, but the effect of this revolution on FPRs is clearly evident in the US data.

A recent World Bank report on gender equality in the Middle East and North Africa (World Bank, 2013) found FPR to be low in the region and the gap between male and female labor force participation to be the highest by world standards. The report did not test the U-shape hypothesis but finds some of its drivers to have developed in the expected direction during the past few decades. The performance of the MENA countries in terms of education and health has been outstanding, with major achievements in terms of declining fertility and mortality rates and in terms of steep improvements in female education. This makes low FPRs in the MENA region the most puzzling unless these countries find themselves at the turning point of the $U$ curve.

This paper returns to the U-shape hypothesis by focusing on MENA countries. To our knowledge, the only paper that tested the U-shape hypothesis in the MENA region is Tsani et al. (2013). This paper uses a pooled regression on 160 countries with the South-Mediterranean countries as the control and then uses the coefficient for these countries to carry out CGE simulations of alternative scenarios. In this paper, we follow a different approach using cross-country panel equations and within countries time-series equations, testing separately for cohorts effects, fertility rates and structural transformation of the economy away from agriculture. We will also test for the role of specific sectors as opposed to GDP in raising FPRs.

\subsection{Models}

We follow here the three most recent contributions to the literature of the U-shape hypothesis (Tam, 2011, Gaddis and Klasen, 2013 and Tsani et al., 2013). The standard equation used to test this hypothesis since the first paper by Goldin (1995) is as follows: 


$$
F L P_{i}=\alpha+\beta_{1} \ln y_{i}+\beta_{2}\left(\ln y_{i}\right)^{2}+\varepsilon_{i},
$$

where $y_{i}$ is typically GDP per capita at Purchasing Power Parity (PPP), and $i$ is a subscript for countries. This is a cross-country equation that is normally applied to one point in time and sometimes replicated over several points in time to test the robustness of results.

Recent data and the availability of longer time-series within countries have allowed for adding a longitudinal dimension to the equation, turning the data into panel data as follows:

$$
F L P_{i t}=\alpha+\beta_{1} \ln y_{i t}+\beta_{2}\left(\ln y_{i t}\right)^{2}+\varepsilon_{i t},
$$

where $t$ represents time. Despite the time dimension and the panel data, Equation (2) is still a cross-section equation in that the coefficients measure the average change in FPR as GDP changes, ignoring the difference between time and country effects. In this case, findings consistent with the U-shape hypothesis essentially state that countries at different levels of development distribute over a U-curve, but nothing is said about the longitudinal shape of the FPR/GDP relation. To add the time dimension and, at the same time, account for time-invariant unobserved heterogeneity, one should run the equation within countries (losing the sample size advantage provided by the multiple countries approach), use country fixed effects in equation (2) or, alternatively, use the first difference equation as follows:

$$
\Delta F L P_{i t}=\gamma_{t}+\beta_{1} \Delta \ln y_{i t}+\beta_{2}\left(\Delta \ln y_{i t}\right)^{2}+\varepsilon_{i t}
$$

Equation (3) is still not optimal because if FPR varies little, lagged FPR is correlated with the error term and the regressors become endogenous. To overcome this last problem and control for endogeneity, one can run a linear dynamic panel data model, such as the Arellano and Bond (1991) model, estimated with a Generalized Method of Moments with Instrumental Variables (AB-GMM) - where the lagged FPR functions as an instrument as shown below with one lag.

$$
F L P_{i t}=\rho F L P_{i t-1}+\beta_{1} \ln y_{i t}+\beta_{2}\left(\ln y_{i t}\right)^{2}+\mu_{i}+\vartheta_{i t},
$$

where $\mu_{i}$ are the fixed effects, and $\vartheta_{i t}$ is the error term. The model in equation (4) accounts for endogeneity but does not account for autocorrelation. Similar estimators include the Arellano and Bover (1995) and Blundell and Bond (1998) estimators, which can account also for autocorrelation. All these estimators are particularly suited for panel data where the number of points in time is smaller than the number of countries, which is the case of our data. However, the Blundell and Bond (1998) types of estimators assume that the instruments (lagged dependent variable) are uncorrelated with the individual effects (country/year). As in Gaddis and Klasen (2013), we find this assumption too restrictive and finally opt to use primarily model (4) for the panel equations. This is also the preferred choice in the recent literature.

The shape of the FPR-GDP per capita relation may be different across group of countries and across individual countries in the MENA region. This is expected and explained by the fact that different groups of countries or individual countries may find themselves transiting on different parts of the $U$ curve during the period considered. We are observing a historic segment of 23 years (1990-2012), which is a longer process 
of economic development and that segment could be located on different parts of the $\mathrm{U}$ curve. Therefore, we need to be cautious on how results of the equations illustrated are interpreted.

A combination of significant coefficients of the type $\hat{\beta}_{1}<0$ and $\hat{\beta}_{2}>0(-/+$ for short) is consistent with a U-shape hypothesis, and this is what the literature considers as evidence of the hypothesis in a cross-country panel setting (see for example Gaddis and Klasen). However, this combination could represent a set of countries that just entered the saddle point of the curve. Vice-versa, a $\hat{\beta}_{1}>0$ and $\hat{\beta}_{2}<0$ combination could indicate an inverted $U$-shape or a set of countries that have passed the saddle point of the $U$ curve and are now experiencing a stagnation of FPRs. These are all cases that can potentially be consistent with a U shape hypothesis. Similarly, combinations of $\hat{\beta}>0$ and $\hat{\beta}_{2}>0$ or $\hat{\beta}_{1}<0$ and $\hat{\beta}_{2}<0$ show accelerations of increasing and decreasing FPRs, respectively, which could be consistent with the long-term hypothesis if these were set of countries that found themselves on the two sides of the U curve.

If the FPR equation is applied to a single country using a longitudinal time series, one has to be even more cautious. The $U$ shape $(-/+$ signs $)$ would show only for those countries which, during the 23 years considered, transited through the saddle point of the curve. This may not be easy to find in the MENA region because most of the MENA countries had already passed in 1990 (year 1 of our analysis) a GDP per capita of 2,5000 USD in PPP values, which is what the global literature found to be the turning point from declining to rising FPRs. This is part of the reason why the literature uses cross-country evidence when individual countries' data series are too short. Hence, while we seek a combination of $(-/+)$ signs for the panel regional regressions to test the U-shape hypothesis, we also need to understand how the individual countries' longitudinal series contribute to shape the form of the curve at the regional level. A graph that combines longitudinal countries time series for all MENA countries will help us to understand the relationship between the within country longitudinal series and the cross-country MENA results.

We will also consider time-series models for individual MENA countries. For this purpose we will use standard OLS models, test for stationarity and correct by instrumenting with lagged dependent variables (OLS-IV). We will also use a reduced version of the Granger model to test how a number of key variables underlying the U-shape hypothesis affect FPRs. The model is as follows:

$$
F L P_{t}=\rho F L P_{t-1}+(\ldots)+\rho F L P_{t-n}+\beta_{1} X_{t-1}+\vartheta_{i t}
$$

where $X$ includes fertility rates, the share of agriculture in total value added, and value added in manufacturing and services. The number of lags of the dependent variable will depend on the stationarity test. The test used is the Breusch-Godfrey test for higherorder serial correlation.

\subsection{Data}

The data on FPRs are collected from the International Labor Organization Economically Active Population, Estimates and Projections (ILO-EAPEP) database. This is the same data used by the quasi totality of cross-country studies reviewed in the previous section. We use the latest edition available at the time of writing ( $6^{\text {th }}$ edition, 2011). 
The rest of the data, including GDP per capita, fertility rates, female education and the share of agricultural value added, are taken from the World Bank open data repository. Additional file 1 provides a full description of the variables used, including the corresponding codes in the World Bank open repository. We have a total of 172 countries, and for all countries, we have 23 annual observations for the period 1990-2012 for both FPR and GDP per capita, with the exceptions of 20 countries where the minimum amount of observations is less than $23 .{ }^{1}$ We use therefore an unbalanced panel in the cross-country models. The full list of countries and years is provided in Additional file 2 .

\section{Results}

We divide the analysis along parametric and nonparametric estimates as this distinction will be important to understand some of the misconceptions about the U-shape hypothesis. The nonparametric analysis is used to review the cross-country and regional evidence, which is in line with much of the worldwide work on the U-shape hypothesis, and to put MENA countries in the context of this type of analysis. The parametric analysis will start from the same premises but will dig further into the within - countries evidence to test the consistency of the hypothesis and determine how well the U-shape hypothesis applies to regions and MENA sub-regions.

\subsection{Nonparametric estimates}

Can economic development explain low FPRs in the MENA region? Take Morocco as an example of the MENA region. If we compare female labor participation in Morocco with that of the US when this country had a similar GDP per capita to Morocco today, then the FPR does not look as low. According to the Maddison's historical data, ${ }^{2}$ GDP per capita in Morocco in 2008 was 3,465 USD. To find the closest value for the US we have to go back to 1889 when the value was 3,413 USD. The FPR in the US in 1890 was $22.1 \%$, which is lower than the FPR observed in Morocco in 2008. The current FPR in Morocco would nicely fit with the U-shape hypothesis, and the long-term trend of low and more recently declining FPR could find an explanation in the context of economic development.

Of course, the US in 1890 and Morocco in 2008 operated in a very different global context. The US, for example, did not face in 1890 the same level of competition from other countries compared with what Morocco faces today from countries such as India and China. In addition, global trade was not as developed in 1890 as it is today. But the level of economic development in terms of a transition from an agrarian to an industrialized society remains as much of a distinctive feature of an economy today as it was 120 years ago. The global context has changed, but some essential elements of the process of economic development remain true. As described in section two of this paper, this is a distinctive assumption of the literature that relates economic development to FPR.

If we reconsider the U-shape hypothesis cross-country using more recent data and bring MENA countries and Morocco into the picture, we find some important stylized facts (Figure 1). First, the U-shape hypothesis holds as it did for Goldin (1995) if we consider more countries and more recent data for 1990, 2000 and 2010. The quadratic fit shown in all panels is clearly U-shaped. Second, and continuing with our Morocco 


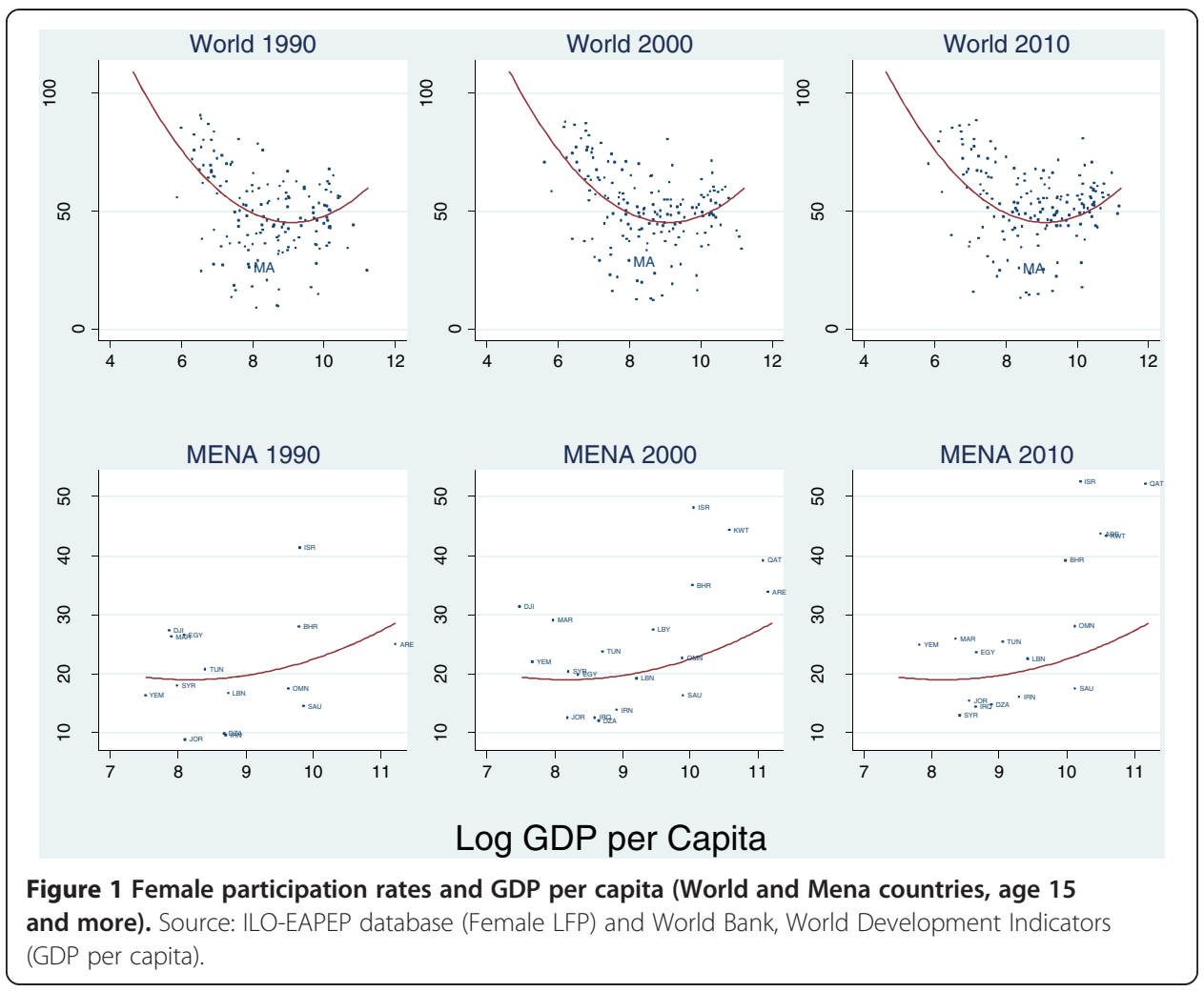

example, Morocco finds itself in correspondence of the bottom of the $\mathrm{U}$ curve in all three time periods. In the long-run of history, Morocco has not moved yet to the upward part of the curve according to the figure, but it could be about to turn the corner. Third, as compared to other world countries at the same level of GDP per capita, Morocco has a lower FPR. Hence, Morocco lags behind relative to other countries at the same level of economic development. Fourth, Morocco appears to move (very) slowly from the downward part towards the upward part if we compare the three points in time considered, although the country remains significantly below the interpolation line throughout the period.

If we plot the same graph for the MENA region only (bottom panels, Figure 1) the U curve holds despite the small number of countries (it is useful here to use Morocco as a reference point to compare the top and bottom panels of the figure). To be precise, many of the MENA countries occupy a particular space of the curve, the section where countries transit from the bottom flat part of the curve to the upward part. As compared to other MENA countries, Morocco exhibits a higher FPR, indicating that Morocco is relatively more advanced among MENA countries. Assuming that MENA countries represent a more homogeneous group than the world countries as a whole, Figure 1 (bottom panel) suggests that there are regional factors that should be able to explain the low FPR in the region. Hence, the behavior of the regional grouping is something we should consider more closely below. ${ }^{3}$

Figure 1 depicts MENA countries as a group of countries that are transiting through the saddle point and towards the upper part of the $U$ curve. This picture is also consistent with the level of GDP per capita. As we saw in the literature review, historically, the transition from the downward to the upward slope occurs at levels of GDP per capita 
around 2,000-3,000 USD. If we exclude resource rich countries for which GDP per capita is a poor indicator of progress, many of the MENA countries considered found themselves around that threshold at the beginning of the period considered (1990). For example, Egypt, Morocco, Jordan, Syria, Yemen and Djibouti all had a GDP per capita in PPP 2005 terms below 4,000 USD in 1990. ${ }^{4}$ The important difference, of course, is that the saddle point for the MENA region is located in correspondence with much lower FPRs than the world as a whole.

A consistent picture also emerges if we consider the building blocks of the $\mathrm{U}$-shape hypothesis, i.e., trends in the economic transformation away from agriculture, female education and fertility rates. Figure 2 shows the change of these three parameters between 1990 and 2010 for all groups of countries considered. ${ }^{5}$ It is immediately evident how well the MENA region has performed. The region is the best performer in terms of fertility rates, the second best performer in terms of female secondary education and also performs above average for the reduction in the share of agricultural values added. The only area where the MENA region has been below the regions' average is GDP per capita, but the MENA region is still above all other regions with the exception of South Asia and Sub-Saharan Africa. The statistics refer to relative percentage changes, and the MENA region still lags behind other regions in terms of these indicators. However, the relative performance of the MENA region has been very positive as compared to other regions in the world. According to this figure, the MENA region has done most things right to turn the corner of FPRs. This largely supports results found in World Bank (2013). This last study also shows that the ratio of female to male unemployment rates is higher in the MENA region than elsewhere, suggesting that labor demand for women is one of the culprits of low FPR in the region.

One of the main arguments behind the U-shape hypothesis is the structural transformation of the economy from agriculture to industry and services. Figure 2 showed that the MENA region performed above the world average in terms of reduction of the share of agricultural output over the period 1990-2012, and this is in line with the U-shape hypothesis. However, for the upward trend of the curve to occur, it is important that

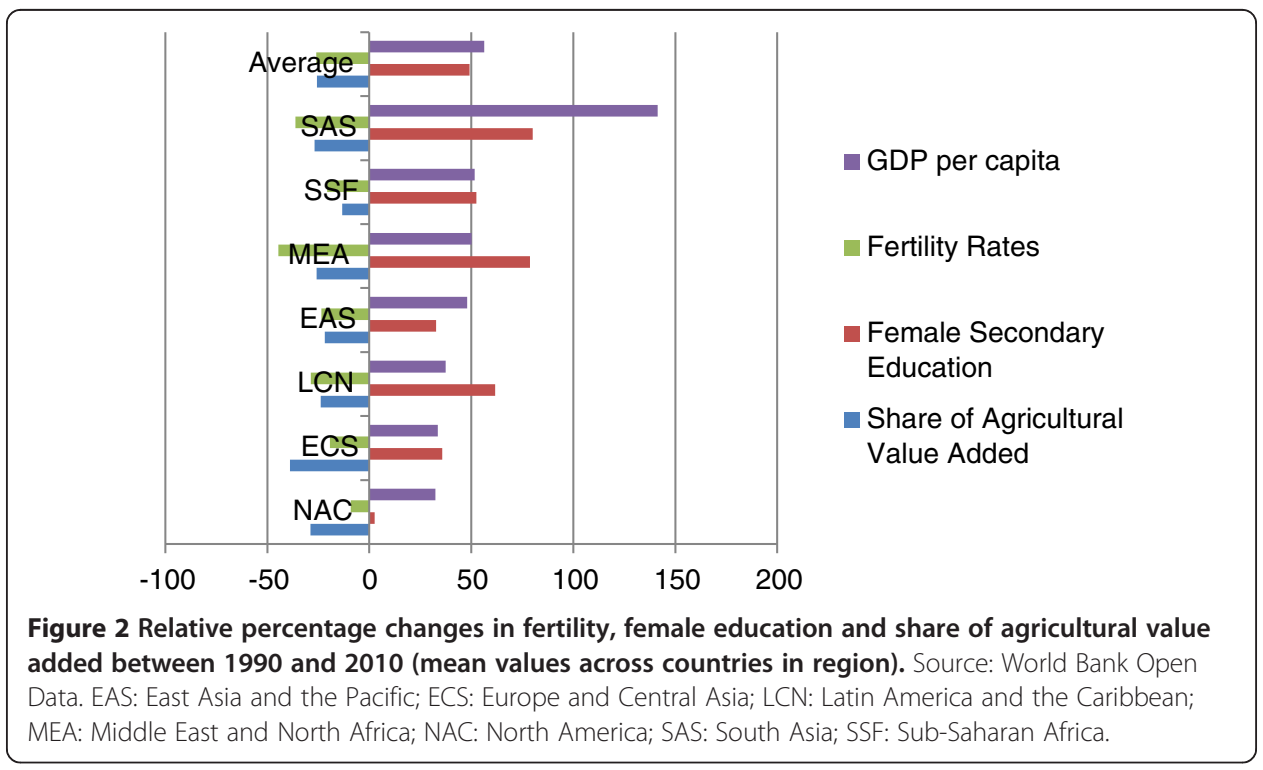


sectors that typically attract women, such as manufacturing and services, increase in output as opposed to sectors that are less likely to attract women, such as heavy industry or mining. Gaddis and Klasen (2013) recently noted that it is important to break down the sectors' shifts in GDP to understand FPRs. If we break down the development of value added shares across sectors and for the world regions, we can see that the MENA region stands out as the only region where the share of agriculture, services and manufacturing all declined between the last decade of the 1990s and the first decade of the 2000s (Table 1, see also Diop et al., 2012). Therefore, the economic restructuring away from agriculture has not favored sectors that are more likely to hire females. The table below shows that this is really a peculiarity of the MENA region as compared to other world regions.

In spite of the positive developments observed for the main drivers of the U-shape hypothesis, we saw in Figure 1 that FPRs in the MENA region are significantly lower than the world taken as a whole. This could be explained by an early exit of women from the labor force or from the fact that certain age groups perform particularly badly, two issues that are usually explored in the U-shape hypothesis literature.

Figure 3 compares FPRs by age group, cohorts and years between the world and the MENA region. The top panel reports the average FPR for women between the age of 20 and 59 divided into five year age groups. For example, point 20 represents the average FPR for age group 20-24 and point 25 the average FPR for age group 25-29. We can see that, worldwide, women have improved participation rates for all age groups and that the increase has been rather consistent across age groups. The best performing age groups are middle-aged groups as compared to young or older groups, which is what determines the hump shape. The overall improvement worldwide is around 7-8 percentage points in terms of participation rates.

The picture changes as we move to MENA countries. On average, FPRs in MENA countries have increased for all age groups between 1990 and 2010. Improvements have been more significant in MENA countries as compared to the world, with increases in the FPR around ten percentage points. However, the hump shape is no longer visible and this is replaced by a negative slope, indicating that older groups always perform worse than younger groups. Essentially, the decline starts around the age of 25, which largely coincides with the marriage age in MENA countries. It is also visible that the improvement experienced by older groups is smaller as compared to improvements of younger groups. ${ }^{6}$

Table 1 Changes in shares of value added (mean 1990-1999 vs. mean 2000-2010)

\begin{tabular}{lllll}
\hline & Services & Agriculture & Industry manufacturing & Industry others \\
\hline East Asia \& Pacific & 4.9 & -4.3 & -1.8 & 1.2 \\
Europe \& Central Asia & 7.8 & -5.1 & -3.8 & 1.1 \\
Latin America \& Caribbean & 2.6 & -3.0 & -1.3 & 1.7 \\
Middle East \& North Africa & -3.0 & -2.6 & -2.2 & 7.8 \\
North America & 1.8 & -0.6 & -2.2 & 1.0 \\
South Asia & 7.7 & -8.1 & -0.4 & 0.8 \\
Sub-Saharan Africa & 2.3 & -4.2 & -1.0 & 2.9
\end{tabular}

Source: World Bank Open data. 


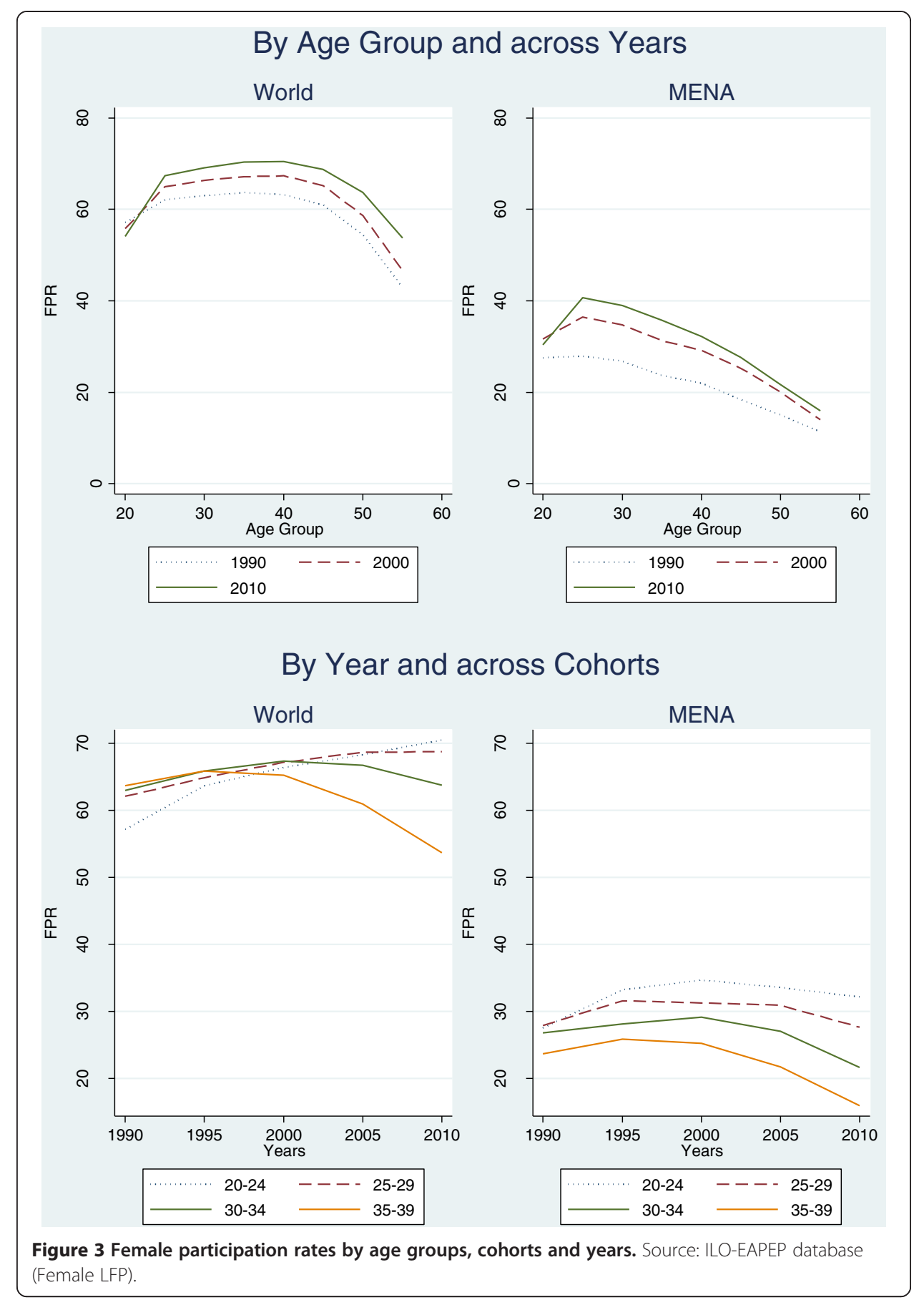

The bottom panel of Figure 3 focuses on population cohorts rather than age groups. Cohorts are defined in terms of the same age groups used in the top panel so that the cohort labeled "20-24" is the one that in 1990 had between 20 and 24 years of age (class of 1966-1970), and the cohort labeled "25-29" is the one that in 1990 had between 25 and 29 years of age (class of 1961-1965). We follow four cohorts labeled with their age in 1990 (20-24, 25-29, 30-34, 35-39) over five years (1990, 1995, 2000, 2005 and 2010). The figure shows that FPRs in the world increased for all cohorts between 1990 and 2000 and continued to increase for the younger (1990) cohorts beyond 2000, while the 
older (1990) cohorts experience a decline in FPRs after 2000. This is probably explained by early retirement as the older cohorts in 1990 (30-34 and 35-39) reached the age of 40-49 in 2000 and 50-59 in 2010.

If we compare the same picture for the MENA region, we find that younger cohorts have consistently better FPRs. However, the start of the decline in FPR offers a mixed picture. It starts after only one period for cohorts 25-29 and 35-39 and after two periods for cohorts 20-24 and 30-34 (recall that labels refer to age in 1990). This means that FPRs start to decline at age 30-34 for the two younger cohorts and at age 40-44 for the two older cohorts. Hence, older cohorts have lower FPRs but their tenure in participation is longer. Overall, these results are fairly consistent with results in the top panel of Figure 3 and point to an early female exit from the labor force, but they also show no improvements in tenure for younger cohorts, which may contribute to the explanation of why MENA countries drag for so long around the saddle point of the curve.

If we had to conclude our analysis at this point, our test of the U-shape hypothesis could be positive with a couple of important caveats. The U-shape relation between GDP per capita and FPRs is evident with the cross-country data, consistent with previous evidence and visible for the MENA region. The fundamental pillars of the hypothesis including the share of agriculture in value added, female education and fertility rates are all consistent with the hypothesis to an extent that the MENA region outperforms other regions of the world. And the MENA countries seemed to be turning the corner (saddle point) in terms of FPRs in four different respects: 1) visually (Figure 1);2) economically, by having passed the GDP per capita threshold and restructured away from agriculture; 3) statistically, by having experienced increases in FPRs and GDP per capita between 1990 and 2010; and 4) socially, by having increased female secondary education and reduced fertility rates.

But we also noted two aspects that make the MENA region stand out as compared to other regions and that are at odds with the U-shape hypothesis. The first aspect is that the MENA region is the only region that was not able to expand the share of both services and manufacturing as opposed to other sectors that are less likely to employ women. Therefore, the overall economic performance is good but not in sectors that would drive female employment. The second is that women in the MENA region seem to exit the labor force around the age of 25 , which largely coincides with the average marriage age in the region. Also, younger cohorts do not seem to improve on tenure in the labor force. These are two important leads to the explanation of persistently low FPRs in the region.

\subsection{Parametric estimates}

In this section, we turn to testing the U-shape hypothesis econometrically and compare the performance of the MENA region with other regions of the world by age group. We will also dig further into the MENA region by testing the U-shape hypothesis by sub-groups of MENA countries and test whether key economic sectors for women can potentially lift FPRs in selected countries.

Results for the FPRs panel regressions are shown in Table 2 for the whole population 15 years and above and for five age groups, 20-24, 25-29, 30-34, 40-44 and 50-54. The first batch of equations (top panel) shows that the U-shape hypothesis stands if we 
Table 2 Female participation rates panel regressions by region and age groups (AB-GMM)

\begin{tabular}{|c|c|c|c|c|c|c|}
\hline Region & Age group & L.FPR & Ingdp & Ingdp2 & Obs. & Signs \\
\hline $\mathrm{ALL}$ & 15plus & $0.875^{* * *}$ & $-2.357^{* *}$ & $0.174^{* * *}$ & 3,472 & $-/+$ \\
\hline EAS & 15plus & $0.840^{* * *}$ & $-4.988^{* * *}$ & $0.314^{* * *}$ & 492 & $-/+$ \\
\hline ECS & 15plus & $0.864^{* * *}$ & $-5.337^{* * *}$ & $0.325^{* * *}$ & 975 & $-/+$ \\
\hline LCN & 15plus & $0.837^{* * *}$ & $16.573^{* *}$ & $-0.752^{*}$ & 553 & $+/-$ \\
\hline MEA & 15plus & $0.896^{* * *}$ & $10.547^{* * *}$ & $-0.535^{* * *}$ & 354 & $+/-$ \\
\hline NAC & 15plus & $0.801^{* * *}$ & $214.551^{* * *}$ & $-10.175^{* * *}$ & 42 & $+/-$ \\
\hline SAS & 15plus & $0.968^{* * *}$ & $10.986^{*}$ & $-0.714^{*}$ & 145 & $+/-$ \\
\hline SSF & 15plus & $0.904^{* * *}$ & $-1.752^{* * *}$ & $0.115^{* * *}$ & 911 & $-/+$ \\
\hline ALL & $20-24$ & $0.813^{* * *}$ & -0.671 & -0.027 & 3,472 & \\
\hline EAS & $20-24$ & $0.845^{* * *}$ & -0.002 & -0.078 & 492 & \\
\hline ECS & $20-24$ & $0.906^{* * *}$ & -4.920 & 0.238 & 975 & \\
\hline LCN & $20-24$ & $0.757^{* * *}$ & $37.134^{* * *}$ & $-1.924^{* * *}$ & 553 & $+/-$ \\
\hline MEA & $20-24$ & $0.790^{* * *}$ & $8.660^{* *}$ & $-0.483^{* *}$ & 354 & $+/-$ \\
\hline NAC & $20-24$ & $0.809^{* * *}$ & $284.109^{* * *}$ & $-13.561^{* * *}$ & 42 & $+/-$ \\
\hline SAS & $20-24$ & $0.940^{* * *}$ & $16.241^{*}$ & $-1.089^{*}$ & 145 & $+/-$ \\
\hline SSF & $20-24$ & $0.876^{* * *}$ & 0.301 & -0.053 & 911 & \\
\hline ALL & $25-29$ & $0.871^{* * *}$ & -2.241 & $0.185^{*}$ & 3,472 & /+ \\
\hline EAS & $25-29$ & $0.839^{* * *}$ & -1.824 & 0.159 & 492 & \\
\hline ECS & $25-29$ & $0.790^{* * *}$ & -2.055 & 0.128 & 975 & \\
\hline LCN & $25-29$ & $0.857^{* * *}$ & 10.191 & -0.395 & 553 & \\
\hline MEA & $25-29$ & $0.888^{* * *}$ & $17.608^{* * *}$ & $-0.883^{* * *}$ & 354 & $+/-$ \\
\hline NAC & $25-29$ & $0.665^{* * *}$ & $322.451^{* * *}$ & $-15.268^{* * *}$ & 42 & $+/-$ \\
\hline SAS & $25-29$ & $0.985^{* * *}$ & $13.959^{*}$ & $-0.920^{*}$ & 145 & $+/-$ \\
\hline SSF & $25-29$ & $0.913^{* * *}$ & $-4.195^{* * *}$ & $0.305^{* * *}$ & 911 & $-/+$ \\
\hline ALL & $30-34$ & $0.896^{* * *}$ & -1.971 & 0.158 & 3,472 & \\
\hline EAS & $30-34$ & $0.871^{* * *}$ & $-3.421^{*}$ & $0.271^{* *}$ & 492 & $-/+$ \\
\hline ECS & $30-34$ & $0.861^{* * *}$ & -3.980 & 0.229 & 975 & \\
\hline LCN & $30-34$ & $0.843^{* * *}$ & 12.142 & -0.477 & 553 & \\
\hline MEA & $30-34$ & $0.903^{* * *}$ & $11.450^{* * *}$ & $-0.577^{* * *}$ & 354 & $+/-$ \\
\hline NAC & $30-34$ & $0.492^{* * *}$ & $459.789^{* * *}$ & $-21.771^{* * *}$ & 42 & $+/-$ \\
\hline SAS & $30-34$ & $0.997^{* * *}$ & $13.063^{*}$ & $-0.859^{*}$ & 145 & $+/-$ \\
\hline SSF & $30-34$ & $0.918^{* * *}$ & $-2.400^{* * *}$ & $0.179 * * *$ & 911 & $-/+$ \\
\hline ALL & $40-44$ & $0.921^{* * *}$ & -1.673 & 0.120 & 3,472 & \\
\hline EAS & $40-44$ & $0.838^{* * *}$ & $-5.670^{* * *}$ & $0.408^{* * *}$ & 492 & $-/+$ \\
\hline ECS & $40-44$ & $0.920^{* * *}$ & -0.301 & 0.029 & 975 & \\
\hline LCN & $40-44$ & $0.844^{* * *}$ & $24.253^{*}$ & -1.132 & 553 & \\
\hline MEA & $40-44$ & $0.896^{* * *}$ & $10.949^{* * *}$ & $-0.552^{* * *}$ & 354 & $+/-$ \\
\hline NAC & $40-44$ & $0.767^{* * *}$ & $272.752^{* * *}$ & $-12.989^{* * *}$ & 42 & $+/-$ \\
\hline SAS & $40-44$ & $0.941^{* * *}$ & 1.445 & -0.053 & 145 & \\
\hline SSF & $40-44$ & $0.917^{* * *}$ & $-3.165^{* * *}$ & $0.222^{* * *}$ & 911 & $-/+$ \\
\hline ALL & $50-54$ & $0.929^{* * *}$ & $-5.528^{* *}$ & $0.385^{* *}$ & 3,472 & $-/+$ \\
\hline EAS & $50-54$ & $0.835^{* * *}$ & $-7.530^{* *}$ & $0.536^{* * *}$ & 492 & $-/+$ \\
\hline ECS & $50-54$ & $0.892^{* * *}$ & $-18.712^{* * *}$ & $1.136^{* * *}$ & 975 & $-/+$ \\
\hline
\end{tabular}


Table 2 Female participation rates panel regressions by region and age groups (AB-GMM) (Continued)

\begin{tabular}{lllllll}
\hline LCN & $50-54$ & $0.800^{* * *}$ & $49.412^{* *}$ & $-2.333^{* *}$ & 553 & $+/-$ \\
MEA & $50-54$ & $0.905^{* * *}$ & 1.923 & -0.067 & 354 & $+/-$ \\
NAC & $50-54$ & $0.790^{* * *}$ & $338.126^{* * *}$ & $-15.914^{* * *}$ & 42 & 145 \\
SAS & $50-54$ & $0.943^{* * *}$ & 3.510 & -0.153 & 911 & $-/+$ \\
SSF & $50-54$ & $0.930^{* * *}$ & $-2.985^{* * *}$ & $0.189^{* * *}$ & \\
\hline
\end{tabular}

Source: ILO-EAPEP database (Female LFP) and World Bank, World Development Indicators (GDP per capita in PPP values). Significance level: ${ }^{* *}=.01 ;{ }^{* *}=.05 ;^{*}=.1$ - *; Standard errors omitted. EAS: East Asia and the Pacific; ECS: Europe and Central Asia; LCN: Latin America and the Caribbean; MEA: Middle East and North Africa; NAC: North America; SAS: South Asia; SSF: Sub-Saharan Africa. Constant term omitted.

consider all countries (Equation "ALL") and the full population in working age, confirming the nonparametric illustration of the GDP-FPR curve shown in Figure 1. However, the breakdown by region and age groups complicates the picture. The quadratic fit stands for all regions, but only four regions have the $-/+$ signs that would conform to the U-shape, while the other half have combinations of significant $+/$ - signs.

If we consider the breakdown by age group, evidence consistent with the $\mathrm{U}$-shape hypothesis almost disappears. The age group 20-24 shows no evidence of a $-1+$ combination across all regions, the age group 25-29 shows -/+ signs only for the SSF region, the age groups 30-34 and 40-44 only for the EAS and SSF regions, and the age group 50-54 for the EAS, ECS and SSF regions. Hence, evidence of a quadratic fit consistent with a U-shape hypothesis is found only in the EAS, ECS and SSF regions and only among older age groups. The MENA region (MEA) shows no evidence of a U-shape for any of the age groups.

For some regions, there is evidence of a $+/$ - combination of signs. This is the case for the population 15 and older of the LCN (Latin America), MEA (Middle East and North Africa), NAC (North America) and SAS (South Asia) regions. The MEA and SAS regions stand out because the $+/$ - signs are rather consistent across age groups. This shows that, once we combine the longitudinal information and take endogeneity into account (as we do with the panel AB-GMM model) the simple quadratic U shape observed in the data in Figure 1 (bottom panel, MENA countries) disappears.

In an effort to better understand the nature of the FPR-GDP relation for the MENA region, we split the region into two groups: Middle income non-oil producing countries and upper income oil-producing countries. To make these two groups as compatible as possible, we selected only six countries for each group including: Morocco, Tunisia, Egypt, Jordan, Syria and Lebanon in the middle-income group and United Arab Emirates, Saudi Arabia, Kuwait, Oman, Qatar and Bahrain in the upper income group. We then repeated the AB-GMM estimations on these two groups separately and for all age groups.

Results show that the two groups differ quite substantially (Table 3). The middle income countries group shows no evidence of any significant quadratic fit in any direction $(-/+$ or $+/-)$. The upper income countries show instead a rather consistent $+/$ - pattern visible for the younger age groups. Hence, while we cannot say much for the first group of countries, the second group of countries has experienced a worsening of the FPR in relation to GDP per capita, particularly for the young. 
Table 3 Female participation rates panel regressions in the Middle East and North Africa by middle and upper income countries (AB-GMM)

\begin{tabular}{lllllll}
\hline & L.FPR & Ingdp & Ingdp2 & cons & Obs. & Signs \\
\hline Middle income countries - non-oil producers & & & & & & \\
15plus & $0.97^{* * *}$ & -2.484 & 0.165 & 10.552 & 124 \\
$20-24$ & $0.882^{* * *}$ & -1.260 & 0.025 & 11.922 & 124 \\
$25-29$ & $0.898^{* * *}$ & 13.903 & -0.759 & -59.841 & 124 \\
$30-34$ & $0.882^{* * *}$ & -10.695 & 0.710 & 43.123 & 124 \\
40-44 & $0.837^{* * *}$ & -16.510 & 1.083 & 65.833 & 124 \\
50-54 & $0.839^{* * *}$ & -8.527 & 0.566 & 34.239 & 124 \\
Upper income countries - oil producers & & & & & \\
15 plus & $0.953^{* * *}$ & $2.924^{* *}$ & $-0.153^{* *}$ & $-11.915^{* *}$ & 106 & $+/$ - \\
$20-24$ & $0.878^{* * *}$ & $6.974^{* * *}$ & $-0.415^{* * *}$ & $-23.214^{* *}$ & 106 & $+/$ - \\
$25-29$ & $0.937^{* * *}$ & $7.742^{* * *}$ & $-0.428^{* * *}$ & $-30.640^{* *}$ & 106 & $+/$ - \\
$30-34$ & $0.949^{* * *}$ & $4.523^{* *}$ & $-0.234^{* *}$ & $-18.845^{* *}$ & 106 & $+/$ - \\
$40-44$ & $0.933^{* * *}$ & 3.056 & -0.139 & -13.687 & 106 & \\
$50-54$ & $0.839^{* * *}$ & 4.054 & -0.160 & -20.872 & 106 & \\
\hline
\end{tabular}

Source: ILO-EAPEP database (Female LFP) and World Bank, World Development Indicators (GDP per capita in PPP values). Significance level: ${ }^{* *}=.01 ;{ }^{* *}=.05 ;{ }^{*}=.1-{ }^{*}$; Standard errors omitted. Middle Income Countries = Morocco, Tunisia, Egypt, Jordan, Syria and Lebanon; Upper Income Countries: United Arab Emirates, Saudi Arabia, Kuwait, Oman, Qatar and Bahrain.

Given that the two groups of countries considered widely differ in terms of GDP per capita, we should expect these two groups to be located on two different segments of the long-term FPR curve. The signs observed in Table 3 could simply describe the FPRGDP relation on different parts of the long-term curve. To verify this hypothesis, we combine the longitudinal time series of each country into one graph so as to have all years and all MENA countries in one graph. This is shown in Figure 4 where the longitudinal series for each country are depicted in different colors.

The figure suggests that the FPR-GDP relation in the region is more complex than a U curve. Middle income countries located in the left part of the figure show a very 'flat' $\mathrm{U}$ shape that does not stand the econometric test of Table 3. Upper income countries located in the right part of the figure show an inverted U-shape, which is also visible in the econometric equations. Therefore, when all MENA countries are aggregated, the inverted U-shape dominates, but the real shape of the curve for the MENA countries is better described as a "wave" or "cosine" curve with a first 'flat' U-shape for middle income countries and a second inverted U-shape for upper income countries. Indeed, the group of countries in the middle (Bahrain, Saudi Arabia and Oman) functions as link between the two curves, thus contributing to shaping the regional wave curve. Hence, the FPR-GDP relation during the process of economic development in the MENA region cannot simply be described as a U-shape.

It is also evident that middle income countries are late comers as compared to the world and stay over the saddle point of the curve for a very long time, while upper income countries reversed the positive FPR growth at low levels of FPRs. The vertical bars in Figure 4 depict different values in USD. The threshold of 2,500 USD (PPP at 2005 prices) - which is what the literature found to be the turning point for FPRs shows that all MENA countries considered were above this threshold for any of the years considered and that, therefore, they should be expected to be well beyond the 


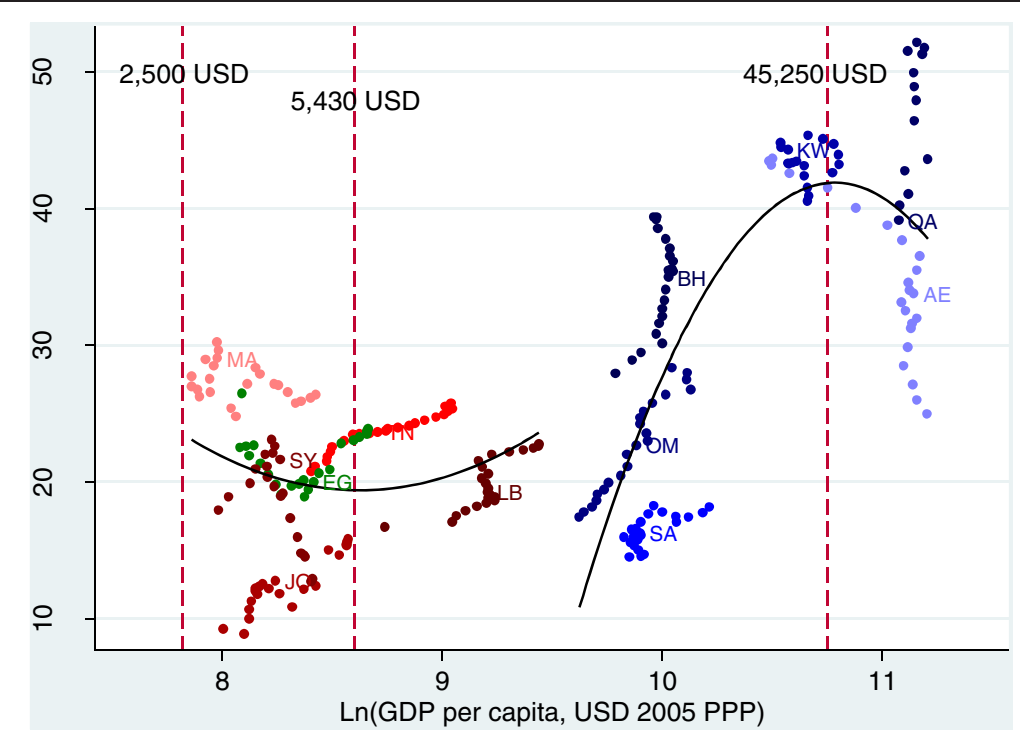

Figure 4 Female participation rates and GDP per capita in the Middle East and North Africa. Source: ILO-EAPEP database. Middle-income countries: MA = Morocco; SY = Syria; EG = Egypt; TN = Tunisia; JO = Jordan; $\mathrm{LB}=$ Lebanon. Upper-income countries: $\mathrm{SA}=$ Saudi Arabia; $\mathrm{OM}=$ Oman; $\mathrm{BH}=$ Bahrain; $\mathrm{KW}=$ Kuwait; $\mathrm{QA}=$ Qatar; $\mathrm{AE}=$ Arab Emirates.

saddle point of the $U$ curve. Instead, the saddle point is found around values of 5,430 USD, and all of the middle income countries seem to have lagged around this saddle point over the full period considered despite significant increases in GDP per capita. Lebanon, which is the only country that really turned the corner in the group, has a GDP per capita well above 10,000 USD. Hence, the performance of middle income countries has been sluggish as compared to the world average.

On the other hand, upper income countries seem to have reversed the positive path at levels of GDP per capita around 45,250 USD. This is the case of Qatar and the United Arab Emirates, while Kuwait seems to find itself around this turning point. This reversal has been observed elsewhere in the world, and most recently in the US, which may suggest that the wave shape may replace the $U$ shape when countries reach very high levels of income per capita. But the important difference between a country like the US and the MENA upper income countries considered is that this reversal occurred at FPRs of around $40 \%$ as opposed to the US where this reversal has occurred at FPRs of around 60\%. In this sense, both groups of MENA countries are underperforming as compared to the world.

What could explain this slow path towards better FPRs for the MENA middle income countries? We saw that these countries performed well in terms of the main drivers of the U-shape hypothesis but poorly in terms of employment generation in key economic sectors for women, such as manufacturing and services. Recall that, in addition to the share of agriculture in output, the literature on FPR has highlighted two other factors that help explain the $U$ shape hypothesis in the long-run. The first is the increased level of female education, especially at the secondary level. Secondary education allows women to take up non-agricultural jobs in the modern sectors and increases the bargaining capacity within the household. The second is the steady decline in fertility that frees some of the time used for household chores. It is therefore instructive to 
include into the $\mathrm{U}$-shape hypothesis equations for fertility and female secondary education and try to see whether the disappointing performance of MENA countries in terms of FPR gains can be explained at least in part by a weak relation between FPRs and female secondary education or fertility rates.

Naturally, there are two problems with including both secondary education and fertility rates in the same FPR equation. The first is that female secondary education and fertility rates are strongly inversely correlated, creating a collinearity problem in the FPR equations. This collinearity, in turn, can artificially alter the sign and significance of the GDP coefficients. The second is that, somehow surprisingly, female secondary education rates are much less available worldwide than fertility rates, FPRs or GDP per capita. The inclusion of female secondary education would make our countries' longitudinal equations too short to run. Forcibly, in what follows, we only use fertility rates on the assumption (widely supported by the literature) that female secondary education and fertility rates are highly inversely correlated.

Following from the above and given the results on the main pillars of the $\mathrm{U}$-shape hypothesis presented in the nonparametric section, we re-run FPR equations using fertility rates, the share of agriculture in value added and the log of value added in services and manufacturing (constant prices, local currency) as independent variables. Here we want to test the contribution of each factor to FPR. Note that we are taking separately the share of agricultural value added, as it is standard for testing the U-shape hypothesis, and the value added of manufacturing and services as indicated by Gaddis and Klasen (2013) in their critique.

Results are shown in Table 4. The fertility rate always has a negative sign when significant, as we should expect, but it is not significant in two of the regions (EAS and ECS). The share of agriculture in value added is significant in four regions and always with the negative sign as expected. The log of manufacturing value added is significant in seven of the eight regions, always with the positive sign except in the Sub-Saharan Africa region. The log of services value added is significant in five regions and always with the positive sign. We should conclude that, at the regional level, the main pillars of the U-shape hypothesis do behave as expected (when significant) and that this is true

Table 4 Female participation rates panel regressions by region, age 15 and above (AB-GMM)

\begin{tabular}{|c|c|c|c|c|c|}
\hline & (1) Fertility rate & $\begin{array}{l}\text { (2) Agricultural } \\
\text { share in value } \\
\text { added }\end{array}$ & $\begin{array}{l}\text { (3) Manufacturing } \\
\text { value added (In, } \\
\text { constant, local curr.) }\end{array}$ & $\begin{array}{l}\text { (4) Services value } \\
\text { added (In, constant, } \\
\text { local curr.) }\end{array}$ & $\begin{array}{l}\text { (5) Number of } \\
\text { observations }\end{array}$ \\
\hline ALL & $-0.412^{* * *}$ & $-0.024^{* * *}$ & $0.416^{* * *}$ & $0.478^{* * *}$ & 3,461 \\
\hline EAS & -0.032 & 0.007 & $0.343^{* * *}$ & 0.010 & 490 \\
\hline ECS & -0.109 & $-0.017^{* * *}$ & $0.385^{* *}$ & $0.331^{* * *}$ & 966 \\
\hline LCN & $-1.594^{* * *}$ & $-0.100^{* * *}$ & $0.804^{*}$ & $3.253^{* * *}$ & 553 \\
\hline MEA & $-0.276^{* * *}$ & -0.015 & $0.373^{*}$ & $0.552^{* * *}$ & 354 \\
\hline NAC & $-2.044^{* * *}$ & -0.047 & $2.116^{* * *}$ & 0.345 & 42 \\
\hline SAS & $-0.334^{* *}$ & -0.025 & 0.370 & 0.154 & 145 \\
\hline SSF & $-0.131^{* * *}$ & $-0.011^{* * *}$ & $-0.137^{* *}$ & $0.148^{* *}$ & 911 \\
\hline
\end{tabular}

Source: ILO-EAPEP database (Female LFP) and World Bank, World Development Indicators for other indicators. Significance level: ${ }^{* *}=.01 ;^{* *}=.05 ;^{*}=.1-{ }^{*}$; Standard errors, lagged variables and constants omitted. EAS: East Asia and the Pacific; ECS: Europe and Central Asia; LCN: Latin America and the Caribbean; MEA: Middle East and North Africa; NAC: North America; SAS: South Asia; SSF: Sub-Saharan Africa. 
for the MENA region. If fertility rates and the share of agricultural value added decrease, FPRs should go up. And if manufacturing and services perform well in terms of output, this should improve FPRs. Hence, the elasticities of changes in in FPRs to changes in key economic sectors are as expected, while we saw that the absolute performance of these sectors has been disappointing.

We can also repeat the exercise above for individual countries using OLS longitudinal models and test for stationarity with a Breusch-Godfrey test. As we found stationarity for most countries, we then corrected by instrumenting lags and finally settled for two lags as the minimum requirement to correct for stationarity in all countries. Given the short time-series available, the options of including other variables in the equations or using cohorts or age groups fixed effects were not considered. The hypothesis is of a linear relation between FPR and these variables in a univariate setting. We run two models, an OLS model with two lags following the stationarity tests already described and a reduced Granger model with two lags (OLS with a lagged independent variable). Countries with less than 10 annual observations were not considered. We also pooled together the sample of countries used and re-estimated the AB-GMM model. Unfortunately, given the sample of countries retained, it was not possible to split the sample across middle income and upper income countries.

Table 5 shows the results. The pooled sample AB-GMM equation confirms that the fertility rate is negative and significant while services and manufacturing are positive and significant as expected. The country specific equations show that the fertility rate is significant in four of the eight countries with the expected negative sign, and these results are consistent across the two models. A reduction in fertility correlates with an increase in FPRs in the MENA region, as observed elsewhere in the world. The agricultural share in value added is significant in three countries, but the sign is not consistent in one country. Additionally, results are not consistent in the two models. Value added in manufacturing explains FPRs in three countries, with the expected positive sign, and these results are consistent across the two models. While the role of services is mostly positive and significant for all except for one country where we find a consistent negative sign in the two models. In essence, fertility rates, manufacturing and services behave as expected, including at the country level, while the role of the share of agricultural output in value added is less clear.

\section{Conclusions}

The paper addressed the question of whether the U-shape hypothesis holds for MENA countries using data covering the period 1990-2012. Nonparametric estimates confirmed previous results that the U-shape hypothesis holds worldwide and cross-country and that the MENA region could fit the trend. The fundamental pillars of the hypothesis including the share of agriculture in value added, female education and fertility rates are all consistent with the hypothesis to an extent that the MENA region outperforms other regions of the world. And the MENA countries seemed to have turned the corner (saddle point) in terms of FPRs in four different respects: 1) visually (Figure 1); 2) economically, by having passed the GDP per capita threshold and restructured away from agriculture; 3) statistically, by having experienced increases in FPRs and GDP per capita between 1990 and 2010; and 4) socially, by having increased female secondary education and reduced fertility rates. 
Table 5 Female participation rates regressions by selected country in the Middle East and North Africa region

\begin{tabular}{|c|c|c|c|c|}
\hline & (1) Fertility rate & $\begin{array}{l}\text { (2) Agricultural } \\
\text { share in value } \\
\text { added }\end{array}$ & $\begin{array}{l}\text { (3) Manufacturing } \\
\text { value added (In, } \\
\text { constant, local curr.) }\end{array}$ & $\begin{array}{l}\text { (4) Services value } \\
\text { added (In, constant, } \\
\text { local curr.) }\end{array}$ \\
\hline \multicolumn{5}{|l|}{ AB-GMM } \\
\hline Pooled sample & $-0.316^{* * *}$ & -0.043 & $0.755^{* * *}$ & $0.885^{* * *}$ \\
\hline \multicolumn{5}{|l|}{ OLS 2 lags } \\
\hline Algeria & 0.058 & -0.006 & $0.783^{* * *}$ & $1.290^{* * *}$ \\
\hline Egypt & $-1.285^{* *}$ & $-0.492^{* * *}$ & $1.907^{* *}$ & $2.470^{* *}$ \\
\hline Jordan & -0.421 & 0.108 & $1.389^{*}$ & $4.564^{* *}$ \\
\hline Lebanon & $-0.573^{* * *}$ & -0.061 & 0.499 & $-1.212^{* * *}$ \\
\hline Morocco & 0.273 & $0.244^{* *}$ & -2.904 & $-1.951^{*}$ \\
\hline Saudi Arabia & $-0.639^{* * *}$ & $-0.211^{* *}$ & $1.526^{* *}$ & 0.877 \\
\hline Tunisia & 0.188 & 0.015 & 0.640 & $0.444^{*}$ \\
\hline Yemen & $-0.444^{* *}$ & -0.042 & -0.656 & 1.052 \\
\hline \multicolumn{5}{|c|}{$\begin{array}{l}\text { Reduced granger } \\
\text { model } 2 \text { lags }\end{array}$} \\
\hline Algeria & 0.030 & $-0.040^{* *}$ & $0.636^{*}$ & $1.117^{* *}$ \\
\hline Egypt & $-1.157^{* *}$ & $-0.500^{* * *}$ & $1.822^{* *}$ & $2.389^{* *}$ \\
\hline Jordan & -0.354 & 0.090 & $1.669^{*}$ & $5.572^{* *}$ \\
\hline Lebanon & $-0.750^{* * *}$ & $-0.096^{*}$ & 0.522 & -0.790 \\
\hline Morocco & 0.324 & 0.161 & -3.021 & $-1.949^{*}$ \\
\hline Saudi Arabia & $-0.645^{* * *}$ & -0.153 & $1.501^{* *}$ & 0.848 \\
\hline Tunisia & 0.174 & 0.008 & 0.676 & $0.469^{* *}$ \\
\hline Yemen & $-0.429^{* *}$ & -0.007 & -0.167 & 0.180 \\
\hline
\end{tabular}

Source: ILO-EAPEP database (Female LFP) and World Bank, World Development Indicators for other indicators. Significance level: ${ }^{* *}=.01 ;^{* *}=.05 ;^{*}=.1-{ }^{*}$; Standard errors, lags and constants omitted. In bold, coefficient changing significance or sign in the Granger model.

There are, however, two aspects that make the MENA region stand out as compared to other regions. The first is that women in the MENA region seem to exit the labor force around the age of 25 , which largely coincides with the average marriage age in the region. This makes the FPR curve by age groups and cohorts downward sloped early on. The second aspect is that the MENA region is the only region that was not able to expand the share of both services and manufacturing as opposed to other sectors that are less likely to employ women. Changes to FPRs in response to changes in key economic sectors are as expected, but the growth in these sectors has not occurred. These are both important leads to understand why the MENA region lags behind in terms of FPRs despite the fundamentals of the U-shape hypothesis.

The parametric estimations show little evidence of a U-shape for the MENA region as a whole. Once we combine the longitudinal information and take endogeneity into account, the simple quadratic $U$ shape observed in in Figure 1 for the MENA countries disappears. However, by splitting the MENA countries in two homogeneous income groups, we found two separate stories that combined originate a wave curve rather than a U curve. The group of MENA middle income countries rests somehow on the saddle point of the curve throughout the period considered, with higher GDP per capita and lower FPRs as compared to the world. This group of countries shows a very "flat" saddle part of the curve that does not stand econometric tests for the U-shape. The group 
of upper income countries shows instead an inverted U-shape which is confirmed by the econometric tests. For this group of countries, the turning point is at high levels of GDP per capita but low levels of FPRs. Hence, both groups of countries have been underperforming as compared to the world panel.

The paper also found that the fundamentals of the U-shape hypothesis are not constraining the expansion of FPRs in the MENA region. The region has outperformed other world regions in terms of reduction of the agricultural share of output, female secondary education and fertility rates. All countries have also significantly expanded in terms of GDP per capita between 1990 and 2010, and they are now well beyond the 2,000-3,000 USD per capita threshold that is considered by the literature the turning point between declining and increasing FPRs. When considering FPR elasticities in response to the share of agricultural output, fertility rates, manufacturing or services value added, results are largely as expected.

We have, therefore, to conclude that the U-shape hypothesis does not describe MENA countries well. These countries are better depicted with a wave curve or with two separate curves for middle income and upper income countries. Explanations for the under-performance of both groups of countries in relation to the world should be sought among two sets of factors. The first is economic and related to the lack of expansion in sectors that we proved critical for expanding female employment like manufacturing and services. The second is cultural and related to the finding that women seem to exit the labor force around marriage age. This paper has not explored the other main pillar of the U-shape hypothesis, which is culture and gender norms, but by exclusion and in view of the cohort analysis, this is one important lead for future research.

\section{Endnotes}

${ }^{1}$ The full list of countries and years is in annex. The country classification used is the international two digits ISO2 classification. Note that ILO-FPR data are missing for most countries before 1990, which explains the choice of the period 1990-2012.

${ }^{2}$ See the Maddison Project: http://www.ggdc.net/maddison/maddison-project/home.htm.

${ }^{3}$ For studies of labor mobility and FPR in Morocco, see Verme et al. (2014a) and Verme et al. (2014b).

${ }^{4}$ World Bank open data. See data section for more details.

${ }^{5}$ Note that for the share of agricultural value added, we considered the average values for the two periods 1990-1999 and 2000-2010 given that agricultural output is subject to significant annual variations.

${ }^{6}$ The MENA curve could also be explained by improvements in education. In countries where female education is increasing fast, younger cohorts will always be more educated than older cohorts, which may explain higher participation rates.

\section{Additional files}

Additional file 1: Key variables.

Additional file 2: Countries and Years (1990-2012). 


\section{Acknowledgments}

The author is grateful to Manuel Arellano, Lidia Ceriani, Abdoul Gadiry-Barry, Jamal Guennauoi, Daniela Marotta, Ernest Sergenti and participants to a seminar held at the World Bank in May 2014 for useful discussions, suggestions and clarifications. All remaining errors are the sole responsibility of the author. The work was financed by the World Bank project P127927. The author is also grateful to the Editor and to one anonymous referee for excellent comments.

Responsible editor: David Lam

Received: 30 September 2014 Accepted: 14 December 2014

Published online: 29 January 2015

\section{References}

Akerlof GA, Kranton RE (2000) Economics and identity. Q J Econ 115:715-753

Angrist JD, Evans WN (1998) Children and their Parents' labor supply: evidence from exogenous variation in family size. Am Econ Rev 88(3):450-477

Arellano M, Bond S (1991) Some tests of specification for panel data: Monte Carlo evidence and an application to employment equations. Rev Econ Stud 58:277-297

Arellano M, Bover O (1995) Another look at the instrumental variables estimation of error components models. J Econometrics 68:29-51

Bloom DE, Canning D, Fink G, Finlay JE (2009) Fertility, female labor force participation, and the demographic dividend J Econ Growth 14(2):79-101

Blundell R, Bond S (1998) Initial conditions and moment restrictions in dynamic panel data models. J Econometrics 87:11-143

Boserup E (1970) Woman's role in economic development. St. Martin, New York

Diop N, Marotta D, de Melo J (ed) (2012) Natural Resource Abundance, Growth, and Diversification in the Middle East and North Africa. The Effects of Natural Resources and the Role of Policies. World Bank Directions in Development, Washington DC

Durand J (1975) The Labor Force in Economic Development: A Comparison of International Census Data 1946-66. Princeton University Press, Princeton, NJ

Gaddis, I and Klasen, S. (2013) Economic Development, Structural Change, and Women's labor force participation. J Popul Econ, doi:10.1007/s00148-013-0488-2

Goldin C. (1995) The U-Shaped Female Labor Force Function in Economic Development and Economic History. In: Schultz T.P. (ed) Investment in Women's Human Capital and Economic Development. University of Chicago Press; Chicago 1995. pp. 61-90

Goldin C (2004) The long road to the fast track: career and family. Ann Am Acad Political Soc Sci 596:20-35

Goldin C (2006) The Quite Revolution that transformed women's employment, education and family. Am Econ Rev 96(2):1-21

Mammen K, Paxson C (2000) Women's work and economic development. J Econ Perspect 14(4):141-164

Olivetti, C. (2013) The Female Labor Force and Long-run Development: The American Experience in Comparative Perspective. In: L. Platt Boustan, C. Frydman, R.A. Margo (forthcoming) Human Capital in History: The American Record. University of Chicago Press; Chicago.

Psacharopoulos G, Tzannatos Z (1989) Female labor force participation: an international perspective. World Bank Res Obser 4:187-202

Tam H (2011) U-Shaped female labor participation with economic development: Some panel data evidence. Econ Lett 110:140-142

Tilly LA, Scott JW (1987) Women, Work and Family. Routledge, New York

Tsani S, Paroussos L, Fragiadakis C, Charalambidis I (2013) Female labor force participation and economic growth in the South Mediterranean countries. Econ Lett 120:323-328

Verme P, Gadiry Barry A, Guennouni J, Taamouti M (2014a) Labor Mobility, Economic Shocks and Jobless Growth: Evidence from Panel Data in Morocco. World Bank Policy Research Working Papers, Morocco, p 6795

Verme P, Gadiry Barry A, Guennouni I (2014b) Female Labor Participation in the Arab World: Some Evidence from Panel Data in Morocco. World Bank Policy Research Working Papers, Morocco. No. 7031

World Bank (2013) Opening Doors. Gender Equality and Development in the Middle East and North Africa. MENA Development Report, World Bank, Washington DC

\section{Submit your manuscript to a SpringerOpen ${ }^{\circ}$ journal and benefit from:}

- Convenient online submission

Rigorous peer review

- Immediate publication on acceptance

- Open access: articles freely available online

- High visibility within the field

- Retaining the copyright to your article

Submit your next manuscript at $\boldsymbol{~ s p r i n g e r o p e n . c o m ~}$ 